\title{
Australian Journal of

\section{Physicochemical characterization of chitosan and its effects on early growth, cell cycle and root anatomy of transgenic and non-transgenic maize hybrids}

\author{
Mayron Martins ${ }^{1}$, Valdir Veroneze-Júnior ${ }^{1}$, Marília Carvalho ${ }^{1}$, Diogo T. Carvalho ${ }^{2}$, Sandro Barbosa ${ }^{1}$, \\ Antônio C. Doriguetto ${ }^{3}$, Paulo C. Magalhães ${ }^{4}$, Cleberson Ribeiro ${ }^{5}$, Marcelo H. dos Santos ${ }^{6}$ and Thiago C. de \\ Souza ${ }^{1, *}$ \\ ${ }^{1}$ Federal University of Alfenas, Institute of Nature Sciences, Street Gabriel Monteiro da Silva, 700, CEP 37130-000, \\ Alfenas-MG, Brazil \\ ${ }^{2}$ Federal University of Alfenas, Faculty of Pharmaceutical Sciences, Street Gabriel Monteiro da Silva, 700, CEP 37130- \\ 000, Alfenas-MG, Brazil \\ ${ }^{3}$ Federal University of Alfenas, Chemical Institute, Street Gabriel Monteiro da Silva, 700, CEP 37130-000, Alfenas- \\ MG, Brazil \\ ${ }^{4}$ National Maize and Sorghum Research Center (Embrapa), BOX 151, CEP 35701-970, Sete Lagoas-MG, Brazil \\ ${ }^{5}$ Federal University of Viçosa, Departament of Chemistry, Street Peter Henry Rolfs, s/n, CEP 36570-000, Viçosa,-MG, \\ Brazil \\ ${ }^{6}$ Federal University of Viçosa, Department of Biology, Street Peter Henry Rolfs, s/n, CEP 36570-000, Viçosa,-MG, \\ Brazil
}

*Corresponding author: thiago.souza@unifal-mg.edu.br

\section{Abstract}

The objectives of this study were to perform the physicochemical characterization of chitosan, to evaluate its effects on germination, early growth, root anatomy and on the cell cycle of two maize hybrids. The hybrids DKB 390 and DKB 390 VTPRO (transgenic) were used. DKB390 VTPRO is from Monsanto, and the event number is 89034, which expresses the proteins Cry1A105 and Cry2AB2. For the physico-chemical characterization of chitosan, the following analyzes were performed:, elemental analysis, total ash, infrared absorption spectroscopy, nuclear magnetic resonance, powder X-ray diffraction, thermogravimetric analysis, scanning electron microscopy and viscosity. With the analysis of infrared absorption spectroscopy, nuclear magnetic resonance, powder X-ray diffraction, thermogravimetric and elemental analysis it was observed that the structure of chitosan presents a low level of deacetylation. Chitosan had a total ash value of $1.32 \%$ and high viscosity. By scanning electron microscopy the chitosan was classified as porous and fibrous structure. Increase in the seed germination rate was observed in both maize hybrids in the presence of chitosan, without changes in the initial growth. The cell analyzes showed that the chitosan was not toxic even at high concentrations, since the mitotic index remained unchanged and no chromosomal abnormalities were detected. The effects of chitosan in root anatomy were evaluated through the measurements of sections of root tips on histological preparations, and the genetically modified hybrid presented the best results. As conclusion, the use of chitosan in appropriate concentrations may favor the development of maize (especially transgenic) acting on germination or changing the root anatomy and consequently increasing resistance and adaptation of the seedlings to adverse conditions.

Keywords: Biostimulant, germination, mitotic index, xylem, Zea mays.

Abbreviations: CT_cortex thickness; DDA\%_degree of deacetylation of chitosan; DTA_differential thermal analysis; ENT_endoderm thickness; ET_epidermal thickness; G\%_germination percentage; GRI_germination rate index; ${ }^{1} \mathrm{H}$-NMR_proton nuclear magnetic resonance; MI_mitotic index; PT_phloem thickness; PXRD_powder x-ray diffraction; RL_root length; RWC_relative water content; SEM_scanning electron microscopy; TGA_thermogravimetric analysis (TGA); xylems number (XN); XT_xylem thickness.

Introduction

Maize is one of the most important crops in the Brazilian agribusiness, and the growing domestic and international demand occurs because is a basic input for poultry and swine, and the main macro-ingredient for the production of animal feed (Caldarelli and Bacchi, 2012). Maize is one of the most important commodities in the world and the major producers are United States, China and Brazil (USDA 2016).
The estimate of total maize production in Brazil for the 2015/16 season was approximately 69.1 million tons (CONAB, 2016). Technologies have been searched to obtain plants more vigorous, more tolerant to stresses, aiming to increase the production. One of these technologies is based on the use of biostimulators, i.e., the use of molecules which 
stimulate plant growth, tolerance to biotic and abiotic stresses, among other factors (Du Jardin, 2015).

Natural polysaccharides, such as chitosan, have been highlighted in researches and the industry of biostimulators due to its biological properties, for being a renewable source, abundant and readily available, with high biodegradability and biocompatibility (Badawy and Rabea, 2011; Du Jardin, 2015; Pichyangkura and Chadchawan, 2015). It is important to emphasize that there is chitosan with different chemical structure inducing different biological responses and it is necessary to perform a physicochemical characterization to understand the structure and activity relationship.

Chitin is a naturally occurring polysaccharide in the exoskeleton of crustaceans, insects, mollusks and the fungal cell wall. After cellulose, the most abundant polysaccharide is chitin. Its structure is similar to cellulose (glucose polymer), differing by the presence of an acetamide nitrogenous group (-NHCOCH3) at the $\mathrm{C} 2$ position. Therefore, chitin can be described as a polysaccharide composed of $\mathrm{\beta}-1,4-\mathrm{N}$-acetylglucosamine monomeric units (Dutta et al., 2004). Chitosan is a deacetylated chitin derivative being structurally similar. Thus, it consists of units of $\mathrm{N}$-acetylglucosamine and glucosamine (Badawy and Rabea, 2011). Chitosan (N-deacetylation) can be obtained by chemical methods with solutions of sodium hydroxide and heating or by fermentative biochemical methods (Kannan et al., 2010).

The use of chitosan in the agriculture has shown good results in plant protection before and after harvest, as an inductor of the plant defense system (against pests and diseases) (Iriti and Varoni, 2015; Li et al., 2015) and of the antagonist action of microorganisms in the biological control (Berger and Stamford, 2011). Also, chitosan increases the interaction between plants and microorganisms (symbiosis) (Kaur and Dhillon 2014), induces increased soil fertility and assists plant nutrition due to its high nitrogen content (Ghormade et al., 2011) and regulates the growth and development of plants (Ramírez et al., 2010; Katiyar et al., 2015). Furthermore, chitosan can even modify the anatomy (Limpanavech et al., 2008) and biochemistry of plants (Dousseau et al., 2016).

Plant researchers are currently using chemical substances on different genotypes of maize and some of these have proved to be more efficient than others (Ali and Ashraf, 2011; Souza et al., 2013). Although there are studies with different genotypes, and despite the importance of transgenics in agriculture worldwide, especially in the cultivation of cereals (Rani and Usha, 2013), there are few comparative studies on the effect of the application of substances in transgenic and non-GMO genotypes.

Chitosan has been used in various concentrations, but its toxic effect has been discussed. Some studies reported cytotoxicity in animal cells (Dash et al., 2011), but there is no information on the toxicity of chitosan in plants. It is known that the solvents used to dissolve chitosan are the responsible for toxicity (Romanazzi, 2009), but the negative effects of high concentrations on the cell cycle of maize plants, such as chromosomal abnormalities, were not assessed.

Due to the importance of the maize crop and the good results obtained with the application of chitosan on plant development, this study aimed to carry out the physicochemical characterization of this biopolymer, to evaluate the effects on germination, early growth, cell cycle and root morphology of two hybrids of Zea mays L. (transgenic and non-transgenic).

\section{Results}

\section{Physicochemical characterization of chitosan}

The chitosan spectrum in the infrared region is shown in Supplementary Fig. 1. The intense band at $3353 \mathrm{~cm}^{-1}$ corresponds to the axial stretching of $\mathrm{OH}$ and $\mathrm{N}-\mathrm{H}$ groups. The peak at $1586 \mathrm{~cm}^{-1}$ corresponds to the angular deformation of $\mathrm{N}-\mathrm{H}$ and $1651 \mathrm{~cm}^{-1}$ corresponds to the axial deformation of $\mathrm{C}=\mathrm{O}$. It may also be noted that the band at $1417 \mathrm{~cm}^{-1}$ corresponds to $\mathrm{C}-\mathrm{N}$ axial deformation of amide groups and the band at $1374 \mathrm{~cm}^{-1}$ shows the axial deformation C-N of amino groups. The bands between 894 and $1149 \mathrm{~cm}^{-1}$ are characteristic of the polysaccharide nature of chitosan.

The elemental analysis showed that the percent of $\mathrm{N}, \mathrm{C}$ and $H$ of chitosan were $7.254,41.850$ and $5.880 \%$, respectively (Table 1 ). The ratio of the percentage of carbon and nitrogen $(\mathrm{C} / \mathrm{N})$ was 5.769 . The degree of deacetylation of chitosan (DDA\%) was $63.5 \%$ (Table 1 ).

After incineration of chitosan, the average percentage of ash was $1.32 \%$ in relation to the air dried chitosan (Table 1 ).

In the ${ }^{1} \mathrm{H}-\mathrm{NMR}$ spectrum (Supplementary Fig. 2), the signals of $\mathrm{H} 3-\mathrm{H} 6$ hydrogen of the glucosamine subunit and $\mathrm{H} 2-\mathrm{H} 6$ of the $\mathrm{N}$-acetylglucosamine subunit were visible as a multiplet in the interval 3.94 to $3.78 \mathrm{ppm}$, while the $\mathrm{H} 2$ of the $\mathrm{N}$-acetylglucosamine subunit generated a signal at about $3.22 \mathrm{ppm}$ due to the influence of the neighboring $\mathrm{NH}$ group. The existence of a signal at about $2.1 \mathrm{ppm}$ relating to the methyl acetamide group confirms the presence of acetylated subunits. The data obtained from the analysis of the subspectra DEPT-135 (Supplementary Fig. 3) corroborate these findings. It is possible to notice the existence of the anomeric carbon ( $\mathrm{C} 1$ ) at $97.6 \mathrm{ppm}$, followed by the signals relating to $C 4, C 3, C 5, C 6$, and $C 2$ at 76.1, 74.6, 69.8, 60.01 and $55.6 \mathrm{ppm}$, respectively. The sign on the methyl group of the acetamide could be viewed at $22 \mathrm{ppm}$. Interestingly, the signal referent to $\mathrm{C} 2$ is duplicated, which demonstrates the existence of $\mathrm{C} 2$ atoms of different natures in the same molecule, due to the partial deacetylation.

The Powder X-ray diffraction (PXRD) pattern of the commercial chitosan used in this work is shown on Supplementary Fig. 4. It exhibits two characteristic broad peaks at $2 \theta \sim 10.0^{\circ}(8.85 \AA)$ and $\sim 19.8^{\circ}(4.50 \AA)$.

The curve of thermogravimetric analysis (TGA) in Supplementary Fig. 5 shows two typical thermal events: the first with a peak at $70-95^{\circ} \mathrm{C}$ with a weight loss of $9 \%$ correspondent to the evaporation of the water present in the hydrophilic groups of the polymer chains. The second event with a peak at $300-380^{\circ} \mathrm{C}$ with weight loss of $65 \%$ is related to the decomposition of glucosamine and residues of $\mathrm{N}$-acetyl glucosamine of the chitosan chains. Differential thermal analysis (DTA) evidenced a large endothermic peak at 55-95으, corroborating the first event of the TGA. Above $200^{\circ} \mathrm{C}$ two strongly exothermic peaks were observed in DTA, typical of the decomposition of chitosan.

Photomicrographs of Scanning Electron Microscopy (SEM) of chitosan showed irregular particles with various sizes and with surfaces flat, fibrous and holes (porous) (Supplementary Fig.6). 
Viscosity was increasing whit increasing concentrations of chitosan, as expected (Fig. 1). The viscosity of the chitosan ranged from 18.5 to $392 \mathrm{mPa} . \mathrm{s}$, evaluated at the concentrations of $0.5-2.5 \mathrm{w} / \mathrm{v} \%$.

\section{Effects of Chitosan on germination and early growth}

No significant differences were observed among the percentage of germination of the hybrids after 48 hours (G\%) of exposure to chitosan. Both hybrids showed significantly higher germination values when exposed to high concentrations of chitosan $(600,1200$ and 2400 ppm) differing statistically from control and other treatments (Fig. $2 \mathrm{~A})$, which indicates that chitosan promoted the increase of maize seed germination percentage. Germination rate index (GRI) was higher for the hybrid DKB 390 exposed to 1200 ppm compared to GM. No significant differences were observed among concentrations in both hybrids (Fig. 2B).

The hybrid DKB 390 showed higher root length (RL) when exposed to treatments 50, 1200 and 2400 ppm and control (Fig. 8C). For this same genotype, RL decreased with the chitosan application, indifferent of the concentration. The GM DKB 390 VTPRO did not present significant changes with treatments, indicating that chitosan did not affect root length (RL), despite the concentration (Fig. 2C).

Regarding the relative water content (RWC) the DKB 390 VTPRO presented higher RWC than DKB 390 after exposure to $50 \mathrm{ppm}$ treatment. RWC of the DKB 390 presented significant decrease when exposed to concentrations of 50 and $150 \mathrm{ppm}$, compared to the other treatments. This response indicates that low concentrations of chitosan reduce water content in the tissues. The DKB 390 VTPRO presented a decrease in RWC with the treatments 150,600, 1200 and $2400 \mathrm{ppm}$, statistically different from the control and other treatments (Fig. 2D).

\section{Effects of Chitosan in the cell cycle}

Fig. 3A shows that the mitotic index (MI) in DKB 390 decreased with the application of chitosan. On the other hand, for transgenic hybrids DKB 390 VTPRO, MI of the cells exposed to $300 \mathrm{ppm}$ concentration of chitosan was similar to the control, i.e., no reduction in the $\mathrm{MI}$ occurred at concentrations below $300 \mathrm{ppm}$. Similar results were found for root length (RL) of the two hybrids (Fig.2C). The interphase was the most frequent stage of the cell cycle in the meristematic cells of roots of the two maize hybrids (Fig.3B and Fig. 3C).

\section{Effects of chitosan on root anatomy}

Comparing the two maize hybrids, the DKB 390 VTPRO exposed to $300 \mathrm{ppm}$ of chitosan solution presented a thickness of root epidermis (ET) significantly higher than the DKB 390 (Fig. 4A). The concentrations of 50 and 600 ppm caused an increase in means of ET in the hybrid DKB 390, but comparable to the control treatment. The concentrations of 150 and $300 \mathrm{ppm}$ caused increase in ET of the DKB 390 VTPRO Hybrid compared to the other treatments (Fig. 4A).

No significant differences between hybrids were observed regarding the cortex thickness (CT). CT of DKB 390 remained unchanged after exposure to various concentrations. Chitosan caused a reduction in TC of the DKB 390 VTPRO exposed to 50 ppm and from 300 ppm (Fig. 4B and Fig. 6).
No significant differences between hybrids were observed for endoderm thickness (ENT). ENT decreased at high concentrations of chitosan (1200 ppm) in both hybrids. However, the transgenic hybrid DKB 390 VTPRO showed a significant increase in EnT in the treatment with $150 \mathrm{ppm}$ of chitosan (Fig. 4C).

The DKB 390 VTPRO presented higher number of xylems (XN) than the DKB 390, but there were no changes in XN in both hybrids comparing the concentrations (except $50 \mathrm{ppm}$ ) (FIG. 5A). The xylem thickness (XT) was significantly higher in DKB 390 at 300 ppm compared to DKB 390 VTPRO. DKB 390 VTPRO showed a decrease of XT with treatments 300,600, 1200 ppm (Fig. 5B and Fig. 7). Again, the chitosan affected plant water relations, especially in the transgenic (DKB 390 VTPRO).

There was no significant difference in the thickness of the phloem (PT) between hybrids. The PT of the hybrid DKB 390 was not affected by different concentrations of chitosan. But the DKB 390 VTPRO had the PT increased at the concentrations of 150 and $300 \mathrm{ppm}$ of chitosan solution compared to the other treatments (Fig. 5C).

\section{Discussion}

For chitosan spectrum in the infrared region, all the characteristic peaks found in the evaluation of chitosan in the present study are very similar to others found in the literature (Paulino et al., 2006; Sagheer et al., 2009; AbdelRahman et al., 2015). When chitin is deacetylated forming chitosan, an increase in the intensity of the peak near 1590 $\mathrm{cm}^{-1}$ and a decrease of the next to $1655 \mathrm{~cm}^{-1}$ occur due to the increased number of $\mathrm{NH}_{2}$ groups. In this study these two bands presented similar intensities indicating a medium to low deacetylation, corroborating the results found for the degree of deacetylation of the chitosan (DDA\%).

The elemental analysis allowed knowing the degree of deacetylation of chitosan, because the most deacetylated present a higher percentage of nitrogen. Conversely, the percentage of carbon decreased due the release of the acetamide group in the deacetylation process. The percentage of nitrogen and carbon found in crustacean chitin by Liu et al., (2012) was 6.24 and 43.75, respectively. Thus the values found in this study were higher than those usually found for chitin, corroborating values found in commercial (Santos et al., 2003) and non-commercial (Abdou et al., 2008; Sagheer et al., 2009; Abdel-Rahman et al., 2015) chitosan.

The most important parameter in the chemical characterization of chitosan is the degree of deacetylation (DDA) (Jana et al., 2013), since affects the physical, chemical and biological properties of chitosan such as acid-base behavior, biodegradability and properties of selfaggregation, sorption, and chelation. The average values for DDA chitosan range from 40 to $95 \%$ (Iriti et al., 2009) and this amplitude of variation occur because are dependent on the method of production, such as temperature, the particle size of raw material, solvents used and the time of contact (Abdel-Rahman et al., 2015). In this study, chitosan presented a low degree of deacetylation. It is important to notice that the processes that lead to the high level of deacetylation are time consuming and costly.

The ash value found in this study differs from that found by Kumari et al., (2015), who obtained chitosan from fishing residue (shrimp and others) with a lower percentage of ash 
$(1.0 \%)$ than the found in this work, but the value is within the commercial chitosan standards. The present data for total ash is justified because the methodology of chitin deacetylation (the concentration of hydrochloric acid, for example) affects the purity of the chitosan; the higher the DDA\%, the lower the percentage of ash (Yuan et al., 2011).

The results of the analysis by proton NMR and DEPT-135 sub-spectra of chitosan showed data coincident with those previously described (Sagheer et al., 2009; Kumirska et al., 2010; Abdel-Rahman et al., 2015; Sayari et al., 2016). The Powder X-ray diffraction (PXRD) pattern of the commercial chitosan exhibits two characteristic broad peaks at $2 \theta \sim 10.0^{\circ}$ $(8.85 \AA)$ and $\sim 19.8^{\circ}(4.50 \AA)$ that correspond to the Miller indices (020) and (110) of the chitosan structure (Yui et al., 1994). The entire PXRD pattern is similar to other recently reported for chitosan (Yen et al., 1994; Sagheer et al., 2009; Shavandi et al., 2015).

The curve of thermogravimetric analysis (TGA) in Supplementary Fig.5 shows two typical thermal events: the first with a peak at $70-95^{\circ} \mathrm{C}$ with a weight loss of $9 \%$ correspondent to the evaporation of the water present in the hydrophilic groups of the polymer chains (Paulino et al., 2006; Abdel-Rahman et al., 2015). The second event with a peak at $300-380^{\circ} \mathrm{C}$ with weight loss of $65 \%$ is related to the decomposition of glucosamine and residues of $\mathrm{N}$-acetyl glucosamine of the chitosan chains (Paulino et al., 2006; Abdel-Rahman et al., 2015; Ma et al., 2015).

The Differential thermal analysis (DTA) results and the curve of Thermogravimetric Analysis (TGA) showed data coincident with those previously described (Paulino et al., 2006; Abdel-Rahman et al., 2015; Ma et al., 2015). In order to observe the real chemical characteristics of chitosan, no pre-drying of the sample was done. Thus, the commercial chitosan presents some moisture since polysaccharides have affinity for water (Sagheer et al., 2009; El-Hefian et al., 2010).

The morphology of the surface of chitosan is variable depending on the species and can be of three types: with pores and fibrous structures; without pores or fibrous structure and only fibrous structure (Kaya et al., 2014). Chitosan derived from crab and shrimp tend to be porous and with fibrous structure as visualized in this study and others (Jayakumar et al., 2008; Sagheer et al., 2009; Shavandi et al., 2015). As far as viscosity is concerned, Ramos et al., (2003) observed greatly lower viscosities of the chitosan of two species of shrimp, using the same concentrations, when compared with the present study.

According to Ferreira and Borghetti (2004), some chemical compounds inhibit the synthesis of gibberellins (GAs) in seeds and, consequently, inhibit germination. The results of the present study suggest that chitosan does not belong to this group of inhibitory compounds, since the use of concentrations; over $600 \mathrm{ppm}$ for 48 hour was beneficial to the germination of maize while lower concentrations did not change the process. Germination rate and germination capacity depend on the incubation conditions of the seeds, according to these authors. Thus, these conditions were apparently favorable in this study (application of chitosan), since no negative effects were observed. Several studies reported that chitosan stimulated seed germination in maize (Guan et al., 2009; Lizárraga-Paulín et al., 2011; Agbodjato et al., 2016) and in other plants (Zeng and Luo, 2012; Mahdav and Rahimi, 2013).

Germination and root length are parameters used in plant bioassays to check phytotoxicity. In the present work the results showed that chitosan is not toxic to maize (mainly DKB 390 VTPRO), but actually may be favorable, acting as a biological stimulator. New concepts have been constructed and Du Jardin (2015) reported that chitosan is a growth promoter, in other words, when applied to the plants increase the nutritional efficiency, quality characteristics of the crop, the tolerance to abiotic stress among others. It is noteworthy that in animal cells the toxicity of chitosan with low percentage of deacetylation (as in this study) is low compared to that with high percentage of deacetylation and molecular weight (Dash et al., 2011).

Although the chitosan at high concentrations negatively affected the RWC of DKB 390 VTPRO seedling, this lower water level compared to the control does not seem to be harmful since no inhibition of root growth (RL) occurred. Chitosan causes stomatal closure and water saving (stabilization of water status) in adult plants grown in soil (Iriti et al., 2009).

The mitotic index (MI) may be used as a cytotoxicity parameter and the reduction of this index, especially in DKB 390 , indicates that chitosan affected the normal development of mitosis, causing blockage of the cell cycle and/or preventing the progression of cells that entered into mitosis (Rijstenbil and Poortvliet, 1992; Fernandes et al., 2007). Thus, chitosan was more cytotoxic to the hybrid DKB 390 when compared to the transgenic DKB 390 VTPRO.

The higher frequency of interphase cells is expected because this is the longest phase of the cell cycle in most eukaryotes. The cell cycle of somatic cells is divided into two phases: interphase and cell division or mitosis. These phases have varying length according to the cell and/or organism studied (Molina et al., 2006). A low frequency of chromosomal abnormalities (CA) was observed for the two hybrids (data not shown) demonstrating that chitosan was not genotoxic in this case. Some cytogenetic studies that evaluated the effect of chitosan application or chitosan nanoparticles in Vicia faba and Allium cepa also found no significant changes in the mitotic index and frequency of chromosomal abnormalities (Lima et al., 2010; Al-Ahamadi, 2015).

Souza et al. (2009), working with maize varieties tolerant and non-tolerant to water stress by flooding, observed that one of the anatomical survival adaptations of tolerant maize is an increase in thickness of the root epidermis, explained as a way to avoid the entrance of pathogens and toxic substances into the root. In this context, the chitosan applied to the substrate may also favor the survival of the maize plants to abiotic and biotic stress by thickening of the root epidermis.

Studies with maize (Chmungu et al., 2014; Chimungu et al., 2015) reported that the smallest thickness of the cortex is important for a more flexibility of the root, facilitating the penetration in compressed/hard soils. The advantage of chitosan in reducing the thickness of the cortex would then be linked to the better penetration in compacted soils, thereby reducing the metabolic cost for the land use and promoting a better development of the plant under some 
Table 1. Elemental analysis (percentage of $\mathrm{N}, \mathrm{C}$ and $\mathrm{H}$ ), ash content, and degree of deacetylation (DDA\%) in chitosan.

\begin{tabular}{|c|c|c|c|c|c|c|}
\hline \multirow{2}{*}{ Sample } & \multicolumn{3}{|c|}{ Content \% } & \multirow[b]{2}{*}{$\mathrm{C} / \mathrm{N}$} & \multirow[b]{2}{*}{ Cinzas } & \multirow[b]{2}{*}{ DDA\% } \\
\hline & $\mathrm{N}$ & $\mathrm{C}$ & $\mathrm{H}$ & & & \\
\hline Chitosan & 7.254 & 41.850 & 5.880 & 5.769 & 1.32 & 63.5 \\
\hline
\end{tabular}

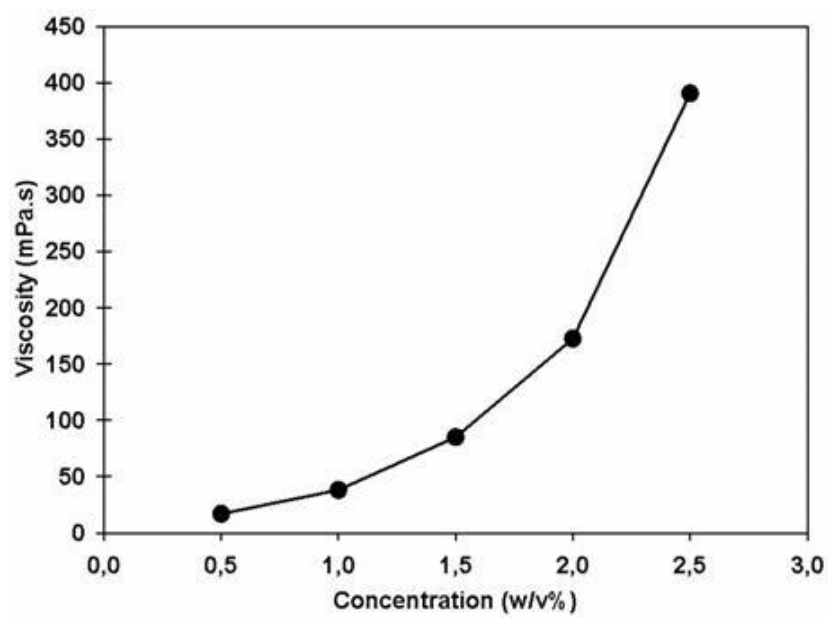

Fig 1. Chitosan viscosity versus concentration. Increase in the viscosity of chitosan due to increased concentration.
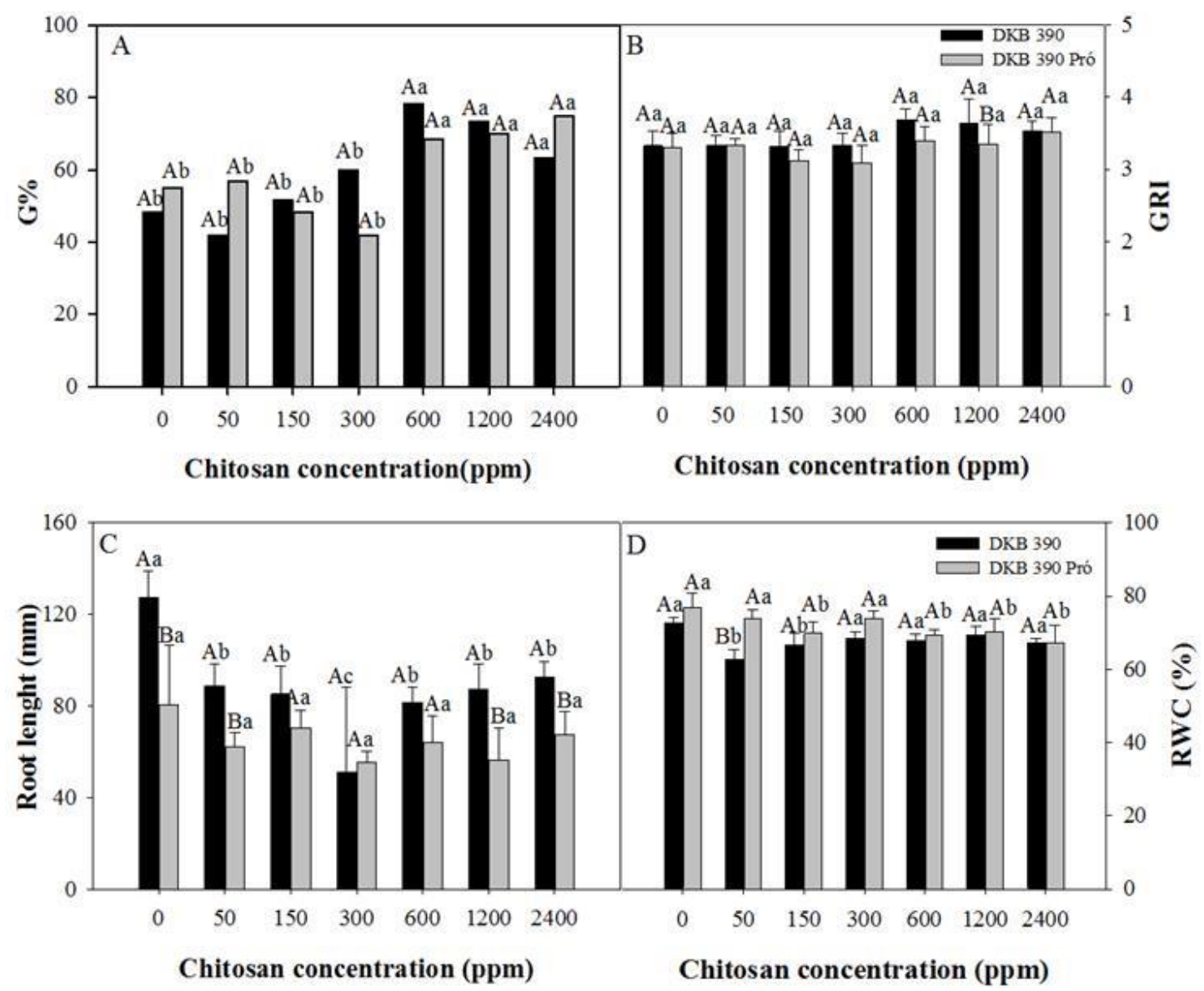

Fig 2. Effect of chitosan on seed germination and early growth of maize (A) Germination percentage (G\%); (B) germination speed index; (C) root length; (D) relative water content of the seedlings (\% RWC). Each bar indicates mean of treatment \pm S.E. Means followed by the same letter (upper case comparing hybrid and lower case comparing concentrations) in each bar does not differ by Skott-Knott test at $5 \%$ probability $(p \leq 0.05)$. 

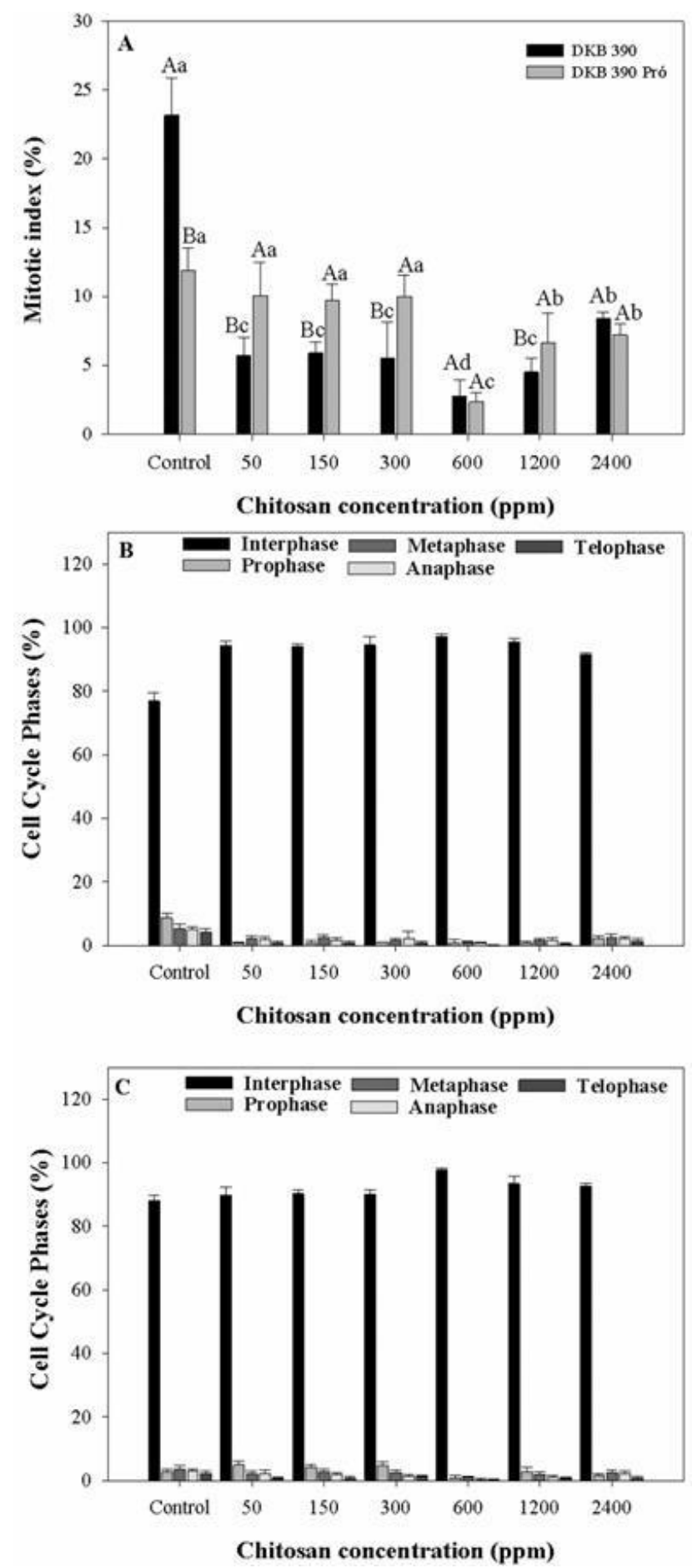

Fig 3. Effect of chitosan on the cell cycle (A) mitotic index (\%); (B) Frequency of the phases of the cell cycle in DKB 390; (C) Frequency of cell cycle phases in DKB 390 VTPRO. Each bar indicates the mean of treatment \pm S.E. Means followed by the same uppercase among the concentrations in each bar does not differ by Skott-Knott test at $5 \%$ probability ( $\leq \leq 0.05)$. Means followed by the same letter (upper case comparing hybrid and lower case comparing concentrations) in each bar does not differ by Skott-Knott test at $5 \%$ probability $(p \leq 0.05)$. 
abiotic stress. The reduction of CT by chitosan can also contribute to a better hydraulic conductivity of the root due to reduction of the distance required for the water reach the vascular cylinder (xylem) (Pereira et al., 2008). The endoderm is a root structure considered as an apoplastic barrier. In maize is formed by a thickening of lignin (and other substances) in form of "U" (Enstone et al., 2003). Chitosan applied in plants can increase the lignin synthesis as a defense mechanism against pests and diseases (El Hadrami et al., 2010). Apparently, the chitosan stimulates the endoderm thickening in the transgenic hybrid. That would be interesting for maize crop, since the epidermis and endoderm of the roots can provide a physical barrier against pathogenic microorganisms (Souza et al., 2009), resulting in healthier plants. At high concentrations (1200 ppm), this thickening was inhibited maybe by inactivating the lignin metabolism due to excess of this substance.

A smaller vessel diameter is related to the decreased risk of embolism and increased resistance of the water flow. These DKB 390 VTPRO characteristics may indicate a higher hydraulic conductivity increasing the water carrying capacity (Li et al., 2009). Although there was no effect of chitosan in the number of xylems, this anatomical feature can also affects the hydraulic conductivity of the roots. Farouk and Mohsen (2011) observed that in cowpea (Vigna unguiculata) the application of chitosan increased the area and number of xylem in leaves.

Souza et al. (2009) reported that the increase in phloem thickness possibly induces a greater flow of carbohydrates, providing more respiratory substrate to the plant, and consequently a greater tolerance to water stress. The results observed in this study suggest that chitosan was beneficial to the seedlings of the hybrid DKB 390 VTPRO since the PT increased. Farouk and Mohsen (2011) also verified in cowpea (Vigna unguiculata) an increase of the phloematic tissue due to the application of chitosan.

\section{Materials and methods}

\section{Physicochemical characterization of chitosan}

The commercial chitosan (Galena Química e Farmacêutica Ltda.) used in this study is derived from shrimp and was applied to all analyzes. The Infrared Absorption Spectroscopy analysis was performed with a Fourier transform infrared spectrophotometer (Thermo Scientific Nicolet, Model iS50) using the attenuated total reflection technique (ATR), with resolution of $4 \mathrm{~cm}^{-1}$ and spectral region $4000-400 \mathrm{~cm}^{-1}$. The elemental analysis was performed using the Elemental Analyzer equipment (Leco Instruments LTD, model TruSpec CHNS-O) according to the procedures specified by the manufacturer. The degree of deacetylation of the chitosan (DDA\%) was calculated as described by Sagheer et al., (2009) using the following formula: (6.857$\mathrm{C} / \mathrm{N}$ ) / 1.7143 , where $\mathrm{C} / \mathrm{N}$ is a carbon percentage ratio by nitrogen measured by elemental analysis. The degree of purity of the chitosan was evaluated by the total ash method according to Abdel-Rahman et al., (2015) with modifications. For the analysis, $1 \mathrm{~g}$ of chitosan was placed in three porcelain crucibles and then incinerated under a gradually increasing temperature in an oven (Magnus, model DM 200F). The temperature gradient used was 30 minutes at $200^{\circ} \mathrm{C}, 60$ minutes at $400^{\circ} \mathrm{C}$ and 90 minutes at $600^{\circ} \mathrm{C}$. The burned

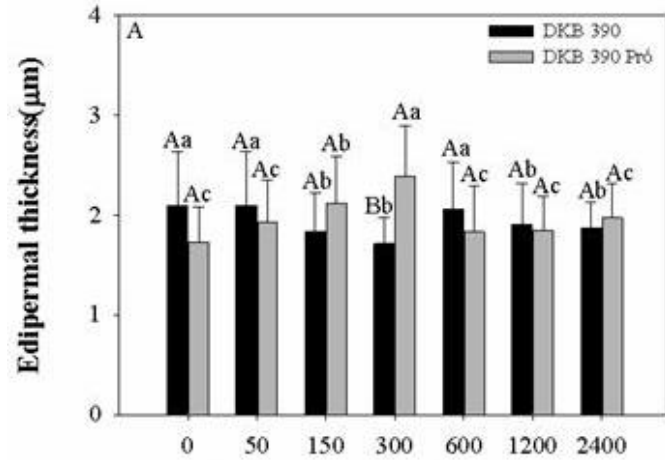

Chitosan concentration (ppm)

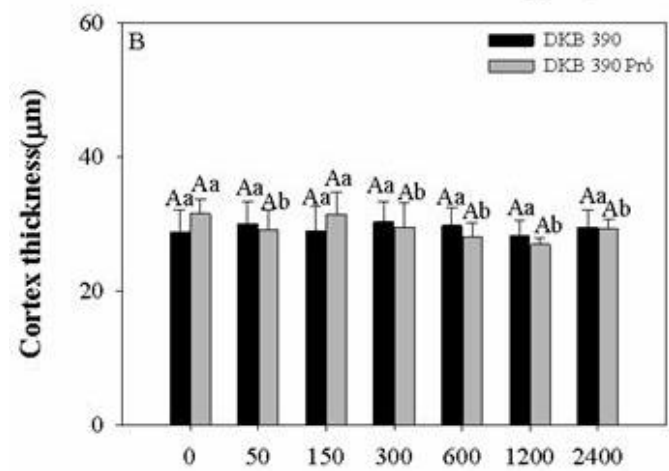

Chitosan concentration (ppm)

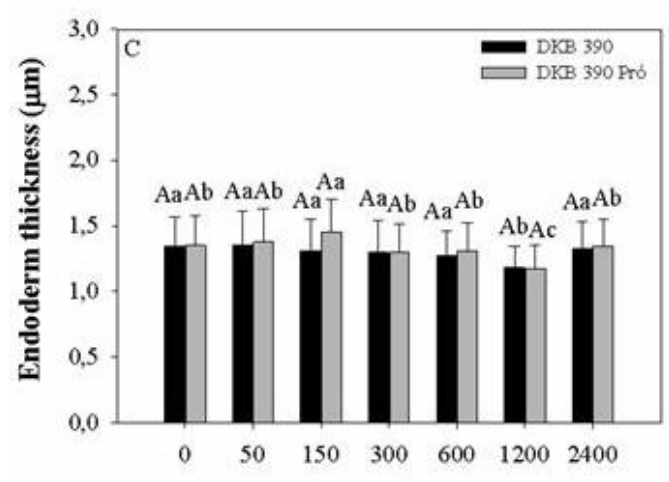

Chitosan concentration (ppm)

Fig 4. Effect of the chitosan on maize root anatomy. (A) Epidermal thickness; (B) cortex thickness; (C) Endoderm thickness. Each bar indicates the mean of treatment \pm S.E. Means followed by the same letter (upper case comparing hybrid and lower case comparing concentrations) in each bar does not differ from each other by Skott-Knott test at 5\% probability $(p \leq 0.05)$.

material was then cooled in a desiccator, weighed, and then calculated the percentage of ash compared to the biopolymer air dried. In order to obtain the spectrum of proton nuclear magnetic resonance $\left({ }^{1} \mathrm{H}-\mathrm{NMR}\right)$ and subspectrum DEPT-135, $10 \mathrm{mg}$ of the sample was solubilized in $1 \mathrm{ml}$ of $\mathrm{HCl} / \mathrm{D}_{2} \mathrm{O} 2 \%(\mathrm{v} / \mathrm{v})$ solution at room temperature. The solution was transferred to a quartz tube NMR $(\Phi=$ $5 \mathrm{~mm})$, and the spectrum was obtained in a spectrometer (Bruker AC-300) operating at $300 \mathrm{MHz}$. The commercial chitosan sample was finely ground and mounted on a grooved glass slide employed as a sample holder. Powder Xray diffraction (PXRD) data was recorded at room temperature $(293 \mathrm{~K})$ using an Ultima IV diffractometer 
(Rigaku, Tokyo, Japan) with $\theta-2 \theta$ geometry. CuK $\alpha$ radiation $(\lambda=1.5418 \AA$ ) was generated using a sealed tube at $40 \mathrm{kV}$ and $30 \mathrm{~mA}$. The data were collected with step size of $0.02^{\circ}$ in 2 $\theta$. The speed of scan was $0.5^{\circ} 2 \theta / \mathrm{min}$. from 3 to $43^{\circ}$ in $2 \theta$. Thermogravimetric analysis (TGA) and differential thermal analysis (DTA) were simultaneously performed using a Netzsch equipment (model 209) at temperature range from room temperature $\left(\sim 25^{\circ} \mathrm{C}\right)$ to $700^{\circ} \mathrm{C}$. Approximately $10.8 \mathrm{mg}$ of the sample were placed into the crucible $\left(\mathrm{Al}_{2} \mathrm{O}_{3}\right)$ under an inert atmosphere with nitrogen flow of $100 \mathrm{ml} / \mathrm{min}$. The heating rate was $10^{\circ} \mathrm{C} / \mathrm{min}$.

The surface morphology of chitosan was analyzed using a digital scanning electron microscope (SEM) (ZEISS LEO model $1430 \mathrm{VP})$. The samples were ground, stored in a desiccator containing silica gel and placed on carbon adhesive tapes in aluminum specimen holders (stubs). The beam current was $500 \mathrm{~Pa}$ and the beam power $20 \mathrm{kV}$. The determination of dynamic viscosity was performed using a rotational viscometer (Quimis, Q-Model 860-A24) using a spindle 1 and speed $60 \mathrm{rpm}$ at $25^{\circ} \mathrm{C}$. The sample was dissolved in acidified water $(0.1 \%)$ and the final volume was $20 \mathrm{ml}$. The viscosity of the chitosan was expressed in terms of concentration.

\section{Plant material and procedures}

The experiments were conducted at the Laboratory of Environmental Biotechnology \& Genotoxicity (BIOGEN) of the Federal University of Alfenas and seeds of two hybrids were used, DKB 390 and DKB 390 VTPRO, the last one GMO. DKB390 VTPRO is from Monsanto, and the event number is 89034, which expresses the proteins Cry1A105 and Cry2AB2. The solutions were prepared by dissolving chitosan in acidified water (acetic acid) $0.1 \%$. The concentrations of the solutions were determined in pretests according to the amount of acetic acid required for dissolution: control $(0.1 \%$ acidified solution) and 50, 150, 300, 600, 1200 and 2400 ppm of Chitosan, moistening two sheets of filter paper disposed in Petri dishes of $12 \mathrm{~cm}$ with $3.6 \mathrm{ml}$ of the each solution. The experimental design was completely randomized, composed by seven treatments (control, 50, $150,300,600,1200$ and 2400 ppm), with 15 seeds per plate and 4 replications. Petri dishes were maintained in a growth chamber type B.O.D. (SOLAB SL-225) at $25^{\circ} \mathrm{C}$ and 12 -hour photoperiod.

\section{Effect of chitosan on germination and early development}

To evaluate the effect of chitosan on seed germination 15 seeds were placed on a petri dish at $25^{\circ} \mathrm{C}$. The germination time lasted for 7 days, when the samplings were performed. Each Petri dish received $3.6 \mathrm{ml}$ of solution (Brasil, 2009). The germination parameters evaluated were: germination percentage (G\%), evaluated after 48 hours of exposure to treatment, and the germination rate index (GRI), assessed each 12 hour for 7 days.

The same method just mentioned, was used to evaluate the effect of chitosan during the initial growth of maize, assessing the parameters root length ( $R L$ ) using a digital caliper, and the relative water content (RWC) calculated by the formula FW - DW / TW - DW X 100, where FW = fresh weight, $\mathrm{DW}=$ dry weight and TW $=$ turgid weight (Souza et al., 2013).
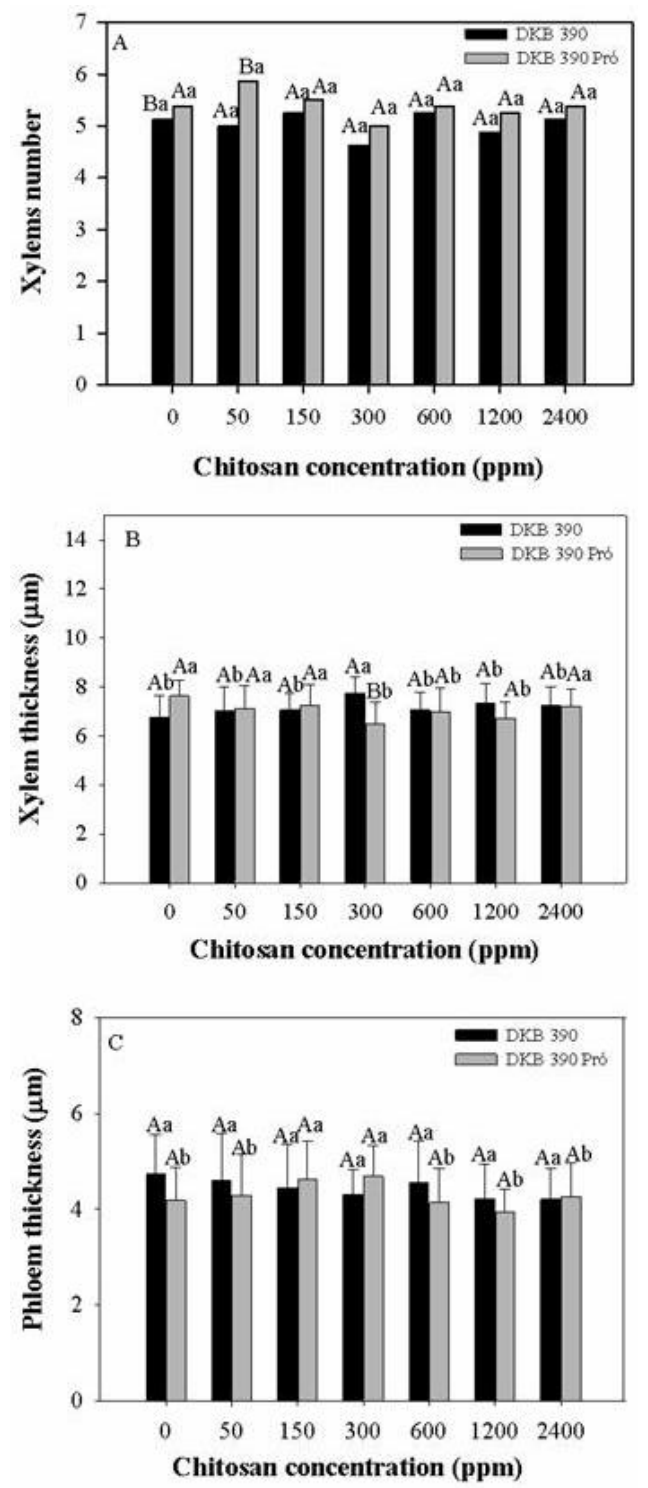

Fig 5. Effect of chitosan on the vascular system of the maize roots. (A) Number of metaxylems; (B) Metaxylem diameter; (C) Phloem thickness. Each bar indicates the mean of treatment \pm S.E. Means followed by the same letter (upper case comparing hybrid and lower case comparing concentrations) in each bar does not differ by Skott-Knott test at $5 \%$ probability $(p \leq 0.05)$.

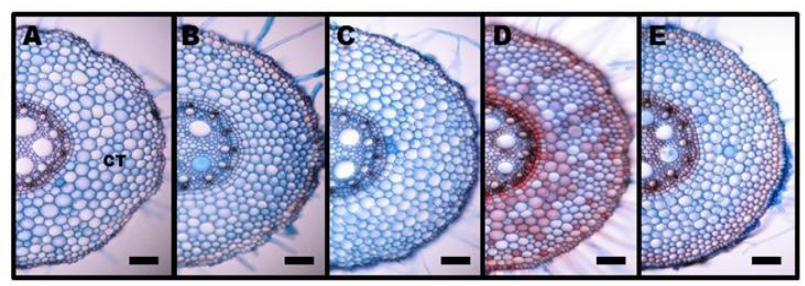

Fig 6. Photomicrographs of cross sections of maize roots (DKB 390 VTPRO) demonstrating the decrease of cortex thickness (CT in the picture) with chitosan application compared to the control. A - control; B - 300 ppm; C - 600 ppm; D - 1200 ppm; E - 2400 ppm. CT = cortex; Bar = 100 @m 


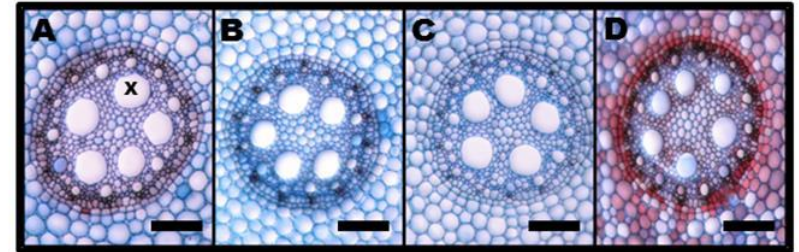

Fig 7. Photomicrographs of cross sections of maize roots (DKB 390 VTPRO) showing the decrease of the thickness of xylem (Letter $X$ in the picture) with chitosan application compared with control. A - control; B - 300 ppm; C - 600 ppm; D - 1200 ppm. $X=x y l e m ; B a r=100$ ?m.

\section{Effects of chitosan on the cell cycle}

To evaluate the cyto/genotoxic effect of chitosan in maize, the squash technique proposed by Pereira et al. (2013) was used, with modifications. Root tips were collected 96 hours after exposure to each concentration of chitosan, followed by fixation in Carnoy (3:1) for 24 hours, hydrolysis in $1 \mathrm{molL}^{-1}$ $\mathrm{HCl}$ at $60^{\circ} \mathrm{C}$ for $8-10$ minutes and pre staining with Shiff Reactive and slides preparation. The slides were evaluated using an optical microscope (NIKON ECLIPSE E200) by analyzing five fields containing 100 cells, totaling 2,000 cells per treatment. The stages of the cell cycle were quantified in order to study the behavior of the chromosome complement.

The mitotic index (MI) was determined using the equation: $\mathrm{MI}=\mathrm{NCM} \times 100 / \mathrm{TNC}$, where NCM is the number of cells in mitosis and TNC the total number of cells evaluated. In addition to the mitotic index, chromosomal abnormalities (CA) were analyzed according to the following criteria: Cmetaphase (CM), chromosome bridges in anaphase (ACB) and telophase (TCB), lost chromosomes (LC), stickiness (ST) and the presence of micronuclei.

\section{Effects of chitosan in root anatomy}

In order to evaluate the effect of chitosan on the root anatomy, two roots of each replication were collected after 7 days of exposure to the treatment, and cross-sections were made according to Souza et al. (2009) in the region of 2 $\mathrm{cm}$ from the root apex. Subsequently, the microscopic slides were prepared, stained with safrablow and photographed in optical light microscope ZEISS AXIO SCOPE A1 with attached digital camera. The parameters evaluated were epidermal thickness (ET), cortex thickness (CT), endoderm thickness (ENT), number of xylems (NX), xylem thickness (XT) and phloem thickness (FT).

All these measurements were made by AxionVisionSE64 image analysis program Rel 4.8, using calibrations made with a microscopic scale photographed in the same amplification of the photomicrographs.

\section{Analysis of biological tests data}

The mean \pm standard error (SE) was calculated for all the analyzed parameters. Analysis of variance (ANOVA) and the mean comparison by Skott-Knott test at $0.05 \%$ significance $(p \leq 0.05)$ using Sisvar program version 4.3 were performed (Federal University of Lavras, Lavras, Brazil).

\section{Conclusion}

It can, therefore, be concluded that chitosan has a low degree of deacetylation, without cytogenotoxic effects. The transgenic maize seedlings (DKB 390 VTPRO) were more responsive to the application of chitosan than nontransgenic seedlings (DKB 390). Chitosan did not affect root length, mainly in the transgenic material, but increased the percentage of germination and caused modifications in the anatomical characteristics linked to the protection and survival to abiotic and biotic stresses.

\section{Acknowledgements}

The authors thank Professor Dr. Maria Vanda Marinho for the thermogravimetric analysis; the Chemical MSc Gustavo Silveira for the viscosimetric analysis; the Foundation for Research of the State of Minas Gerais (FAPEMIG) and the National Scientific and Technological Development Council (CNPq) for the financial support (APQ-00651-14) and the grant of Scientific Initiation scholarship through institutional quotas.

\section{References}

Abdel-Rahman RM, Hrdina R, Abdel-Mohsen AM, Moustafa AM, Fouda MG, Soliman AY, Mohamed FK, Mohsin K, Pinto TD (2015) Chitin and chitosan from brazilian atlantic coast: isolation, characterization and antibacterial activity. Int J Biol Macromol. 80: 107-120.

Abdou ES, Khaled AS, Elsabee NM (2008) Extraction and characterization of chitin and chitosan from local sources. Bioresource Technol. 99: 1359-1367.

Agbodjato NA, Noumavo PA, Adjanohoun A, Agbessi L, BabaMoussa L (2016) Synergistic effects of plant growth promoting rhizobacteria and chitosan on in vitro seeds germination, greenhouse growth, and nutrient uptake of maize (Zea mays L.). Biotechnol Res Int. 2016: 1-11.

Al-Ahamadi MS (2015) Cytogenetic effect of chitosan on mitotic chromosomes of root tip cells of Vicia faba. Life Sci J. 12: 158-162.

Ali $Q$, Ashraf $M$ (2011) Induction of drought tolerance in maize (Zea mays L.) due to exogenous application of trehalose: growth, photosynthesis, water relations and oxidative defense mechanism. J Agron Crop Sci. 197: 258271.

Badawy MEl, Rabea El (2011) A biopolymer chitosan and its derivatives as promising antimicrobial agents against plant pathogens and their applications in crop protection. Int J Carbohyd Chem. 2011: 1-29.

Berger LRR, Stamford TCM, Stamford NP (2011) Prospects for the use of chitosan in agriculture. Rev Iberoam Polímeros. 12: 195-215.

BRAZIL. Ministry of Agriculture, Livestock and Food Supply (2009). Rules for seed testing /Ministry of Agriculture, Livestock and Supply. Agricultural Defense Secretariat. Brazil, Brasília: Mapa/ACS.

Caldarelli CE, Bacchi MEP (2012) Factors influencing the price of corn in Brazil. New Econ. 22: 141-164.

Chimungu JG, Brow KM, Lynch JP (2014) Reduced root cortical cell file number improves drought tolerance in maize. Plant Physiol. 166: 1943-1955. 
Chimungu JG, Loades KW, Lynch JP (2015) Root anatomical phenes predict root penetration ability and biomechanical properties in maize (Zea mays), J Exp Bot. 66: 3151-3162.

CONAB - National Supply Company (2016) Monitoring of the Brazilian grain harvest: tenth Survey, July / 2016. http://www.conab.gov.br, 2016.

Dash M, Chiellini F, Ottenbrite RM, Chiellini E (2011) Chitosan - A versatile semi-synthetic polymer in biomedical applications, Prog Polym Sci. 36: 981-1014.

Dousseau S, Rodrigues AC, Lira JMS, Ribeiro Júnior PM, Pacheco FV, Alvarenga AA, Resende MLV, De Paula ACCFF (2016) Exogenous chitosan application on antioxidant systems of Jaborandi. Ciênc Rural. 46: 191-197.

Du Jardin P (2015) Plant biostimulants: Definition, concept, main categories and regulation. Sci Hortic 196: 3-14.

Dutta PK, Dutta J, Tripathi V S (2004) Chitin and chitosan: chemistry, properties and applications. J Sci Ind Res. 63: 20-31

El Hadrami A, Adam LR, El Hadrami I, Daayf F (2010) Chitosan in plant protection. Mar Drugs. 8: 968-987.

El-Hefian EA, Elgannoudi ES, Mainal A, Yahaya AH (2010). Characterization of chitosan in acetic acid: rheological and thermal studies. Turk J Chem. 34: 47-56.

Enstone DE, Peterson A, Ma F (2003) Root endodermis and exodermis: structure, function, and responses to the environment. J Plant Growth Regul. 21: 335-351.

Farouk S, El Mohsen AR (2011) Improving growth and yield of cowpea plant by foliar application of chitosan under water stress. J Plant Prod. 2: 1341-1358.

Fernandes R, Luz W, Fontes M, Fontes L (2007) Evaluation of heavy metal concentrations in vegetable crop cultivation areas in Minas Gerais, Brazil. Rev Bras Eng Agr Amb. 11: 81-93.

Ferreira AG, Borghetti F (2004) Germination: From basic to applied, first ed., Artmed. Brazil

Georgieva V, Zvezdova D, Vlaev L (2012) Non-isothermal kinetics of thermal degradation of chitosan. Chem Cent. J 6: 1-10.

Ghormade V, Deshpande MV, Paknikar KM (2011) Perspectives for nano-biotechnology enabled protection and nutrition of plants. Biotechnol Adv. 29: 792-803.

Guan Y, Hu J, Wang X, Shao C (2009) Seed priming with chitosan improves maize germination and seedling growth in relation to physiological changes under low temperature stress. J Zhejiang Univ Sci B. 10: 427-433.

Iriti M, Picchi V, Rossoni M, Gomarasca S, Ludwig N, Gargano $M$, Faoro $F(2009)$ Chitosan antitranspirant activity is due to abscisic acid-dependent stomatal closure. Environ Exp Bot. 66: 493-500.

Iriti M, Varoni EM (2015) Chitosan-induced antiviral activity and innate immunity in plants. Environ Sci Pollut Res. 22: 2935-2944.

Jana S, Saha A, Nayak AK, Sen K K, Basu SK (2013) Aceclofenac-loaded chitosan-tamarind seed polysaccharide interpenetrating polymeric network microparticles. Colloid Surface B. 105: 303-309.

Jayakumar R, Nagahama H, Furuike T, Tamura H (2008) Synthesis of phosphorylated chitosan by novel method and its characterization. Int J Biol Macromol. 42: 335-339.

Kannan M, Nesakumari M, Rajarathinam K, Ranjit Singh AJA (2010) Production and characterization of mushroom chitosan under solidstate fermentation. Adv Biol Res. 4: 10-13.
Katiyar D, Hemantaranjan A, Singh B (2015) Chitosan as a promising natural compound to enhance potential physiological responses in plant: a review. Ind J Plant Physiol. 20:1-9.

Kaur S, Dhillon GS (2014) The versatile biopolymer chitosan: potential sources, evaluation of extraction methods and applications Crit Rev Microbiol. 40: 155-175.

Kaya M, Baran T, Mentes A, Asaroglu M, Sezen G, Tozak KO (2014) Extraction and characterization of $\alpha$-chitin and chitosan from six different aquatic invertebrates. Food Biophys. 9: 145-157.

Kumari S, Rath P, Kumar SHA, Tiwari TN (2015) Extraction and characterization of chitin and chitosan from fishery waste by chemical method. Environ Technol Innov. 3: 7785.

Kumirska J, Czerwicka M, Kaczyński Z, Bychowska A, Brzozowski K, Thöming J, Stepnowski P (2010) Application of spectroscopic methods for structural analysis of chitin and chitosan. Mar Drugs. 8: 1567-1636.

Li H, Wang Y, Liu F, Yang Y, Wu Z, Cai H, Zhang Q, Wang Y, Li $P$ (2015) Effects of chitosan on control of postharvest blue mold decay of applefruit and the possible mechanisms involved. Sci Hortic. 186: 77-83.

Li Y, Sperry JS, Shao M (2009) Hydraulic conductance and vulnerability to cavitation in corn (Zea mays L.) hybrids of differing drought resistance. Environ Exp Bot. 66: 341-346.

Lima R, Feitosa L, Pereira AES, Moura MR, Aouada FA, Mattoso LHC, Fraceto LF (2010) Evaluation of the genotoxicity of chitosan nanoparticles for use in food packaging films. J Food Sci. 75: 89-96.

Limpanavech $\mathrm{P}$, Chaiyasuta $S$, Vongpromek R, Pichyangkura $R$, Khunwasi $C$, Chadchawan $S$, Lotrakul $P$, Bunjongrat $R$, Chaidee A, Bangyeekhun T (2008) Chitosan effects on floral production, gene expression, and anatomical changes in the Dendrobium orchid. Sci Hortic. 116: 65-72.

Liu S, Sun J, Yu L, Zhang C, Bi J, Zhu F, Qu M, Jiang C, Yang Q (2012) Extraction and characterization of chitin from the beetle Holotrichia parallela Motschulsky, Molecules. 17: 4604-4611.

Lizárraga-Paulín EG, Torres-Pacheco I, Moreno-Martínez E, Miranda-Castro SP (2011) Chitosan application in maize (Zea mays) to counteract the effects of abiotic stress at seedling level. Afr J Biotechnol. 10: 6439-6446.

Ma L, Xin C, Tan C (2015) Preparation, physicochemical and pharmaceutical characterization of chitosan from Catharsius molossus residue, Int J Biol Macromol. 80: 547556.

Mahdav B, Rahimi A (2013) Seed priming with chitosan improves the germination and growth performance of ajowan (Carum copticum) under salt stress. Eurasian J Biosci. 7: 69-76.

Molina TF, Tillmann MÂA, Dode LB, Viégas L (2006) Cryoconservation in onion seeds. Rev Bras Sementes. 28: 72-81.

Paulino AT, Simionato JI, Garcia JC, Nozaki J (2006) Characterization of chitosan and chitin produced from silkworm crysalides. Carbohyd Polym. 64: 98-103.

Pereira FJ, Castro EM, Souza TC, Magalhães PC (2008) Evolution of the root anatomy of 'Saracura' maize in successive selection cycles. Pesq Agropec Bras. 43: 16491656.

Pereira MP, Pereira FJ, Rodrigues LCA, Barbosa S, Castro EM (2013) Lead phytotoxicity on germination and early growth 
of lettuce as a function of root anatomy and cell cycle. Rev Agroambiente. On-line 7: 36-43.

Pichyangkura R, Chadchawan S (2015) Biostimulant activity of chitosan in horticulture. Sci Hortic. 196: 49-65.

Ramírez MA, Rodríguez AT, Alfonso L, Peniche C (2010) Chitin and its derivatives as biopolymers with potential agricultural applications. Biotecnología Aplicada. 7: 270276.

Ramos VM, Rodríguez NM, Díaz MF, Rodríguez MS, Heras A, Agulló E (2003) N-methylene phosphonic chitosan. Effect of preparation methods on its properties. Carbohyd Polym. 52: 39-46.

Rani J, Usha R (2013) Transgenic plants: types, benefits, public concerns and future. J Pharm Res. 6: 879-883.

Rijstenbil LW, Poortvliet TCW (1992) Copper and zinc in estuarine water: chemical speciation in relation to bioavailability to the marine planktonic diatom Ditylum brightwellii. Environ Toxicol Chem. 11: 1615-1625.

Romanazzi G (2009) Effect of chitosan dissolved in diferente acids on its abity to control postarvest gray moldo of table grape. Phytophatology. 99: 1028-1036.

Sagheer FA, Al-Sughayer MA, Muslim S, Elsabee MZ (2009) Extraction and characterization of chitin and chitosan from marine sources in Arabian Gulf. Carbohyd Polym. 77: 410419.

Santos JE, Soares JP, Dockal ER (2003) Characterization of comercial chitosan from different suppliers. Polímeros. 13: 242-249.

Sayari N, Sila A, Abdelmalek BE, Abdallah RB, EllouzChaabouni S, Bougatef A, Balti R (2016) Chitin and chitosan from the norway lobster by-products:antimicrobial and anti-proliferative activities. Int J Biol Macromol. 87: 163171.
Shavandi A, Bekhit AA, Bekhit, Sun Z, Ali MA (2015) Preparation and characterisation of irradiated crab chitosan and New Zealand arrow squid pen chitosan. Mater Chem Phys. 167: 295-302.

Souza TC, Castro EM, Pereira FJ, Parentoni SN, Magalhães PC (2009) Morpho-anatomical characterization of root in recurrent selection cycles for flood tolerance of maize (Zea mays L.). Plant Soil Environ. 55: 504-510.

Souza TC, Magalhães PC, Castro EM, Albuquerque PEP, Marabesi MA (2013) The influence of ABA on water relation, photosynthesis parameters, and chlorophyll fluorescence under drought conditions in two maize hybrids with contrasting drought resistance. Acta Physiol Plant. 35: 515-527.

USDA -United States Departament of Agriculture (2016) Second estimate of commodity 2016/2017. http://www.usda.gov, 2016.

Yen M-T, Yang J-H, Mau J-L (2009) Physicochemical characterization of chitin and chitosan from crab shells. Carbohyd Polym. 75: 15-21.

Yuan Y, Chesnutt BM, Haggard WO, Bumgardne JD (2011) Deacetylation of chitosan: material characterization and in vitro evaluation via albumin adsorption and preosteoblastic cell cultures. Materials. 4: 1399-1416.

Yui T, Imada K, Okuyama K, Obata Y, Suzuki K, Ogawa K (1994) Molecular and crystal structure of the anhydrous form of chitosan. Macromolecules. 27: 7601-7605.

Zeng D, Luo X (2012) Physiological effects of chitosan coating on wheat growth and activities of protective enzyme with drought tolerance. Open J Soil Sci. 2: 282-288. 